\title{
Epidermal Stem Cells in Skin Wound Healing
}

\author{
Yuanyuan $\mathrm{Li}^{*}{ }^{*}$ Jamie Zhang, Jiping Yue, Xuewen Gou, and Xiaoyang $\mathrm{Wu}^{*}$ \\ Ben May Department for Cancer Research, The University of Chicago, Chicago, Illinois.
}

Significance: Skin serves as a protective barrier for mammals. Epidermal stem cells are responsible for maintaining skin homeostasis. When cutaneous injuries occur, skin homeostasis and integrity are damaged, leading to dire consequences such as acute, chronic, or infected wounds. Skin wound healing is an intrinsic self-saving chain reaction, which is crucial to facilitating the replacement of damaged or lost tissue.

Recent Advances: An immense amount of research has uncovered the underlying mechanisms behind the complex and highly regulated wound healing process. In this review, we will dissect the biological process of adult skin wound healing and emphasize the importance of epidermal stem cells during the wound healing.

Critical Issues: We will comprehensively discuss the current clinical practices used on patients with cutaneous wounds, including both traditional skin grafting procedures and advanced grafting techniques with cultured skin stem cells. The majority of these leading techniques still retain some deficiencies during clinical use. Moreover, the regeneration of skin appendages after severe injuries remains a challenge in treatment.

Future Directions: Understanding epidermal stem cells and their essential functions during skin wound healing are fundamental components behind the development of clinical treatment on patients with cutaneous wounds. It is important to improve the current standard of care and to develop novel techniques improving patient outcomes and long-term rehabilitation, which should be the goals of future endeavors in the field of skin wound healing.

Keywords: epidermal stem cells, skin, wound repair, tissue regeneration

\section{SCOPE AND SIGNIFICANCE}

As A PART OF THE largest organ in the adult mammalian body, the skin epidermis has significant functions in protecting the host from the external environment (e.g., irradiation, pathogen, dehydration, and physical stress) and maintaining skin appendages. When cutaneous wounds occur, damaged epidermis requires an appropriate healing process to repair or regenerate skin. We will discuss the biological process of adult skin wound healing and the contributions of epidermal stem cells dur- ing these steps. We will also discuss the implementation of current clinical approaches in wound treatment that are closely based upon epidermal stem cells.

\section{TRANSLATIONAL RELEVANCE}

In adult skin wound healing, fibrosis and scar formation are the main forms of skin repair, during which many types of cells, growth factors, and cytokines orchestrate and fulfill the closure of the skin wound. Epidermal stem cells play essential roles during wound healing

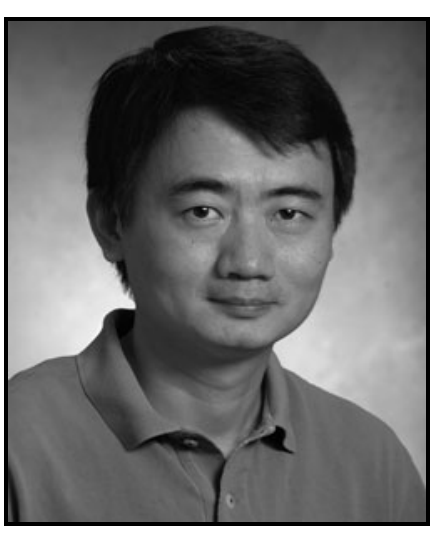

Xiaoyang Wu, PhD

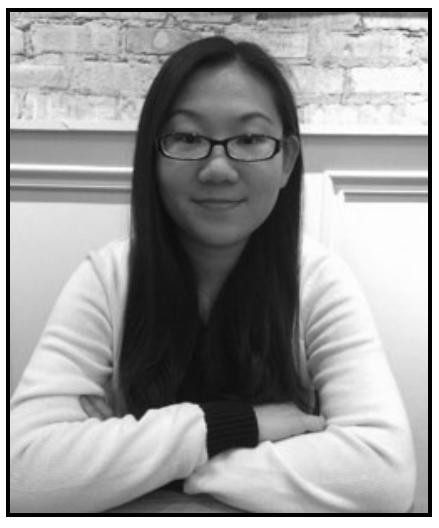

Yuanyuan Li, MS

Submitted for publication January 27, 2017. Accepted in revised form March 13, 2017.

*Correspondence: Ben May Department for Cancer Research, The University of Chicago, GCIS W408B, 929 E 57th Street, Chicago, IL 60637

(e-mail: xiaoyangwu@uchicago.edu). 
process, and the mechanisms controlling keratinocyte functions are fundamental questions that need to be answered. The standard of care for patients with cutaneous wounds is dependent on the crucial function of epidermal stem cells.

\section{CLINICAL RELEVANCE}

Although skin grafting is still commonly used to treat patients with cutaneous wounds, there are some limitations and deficiencies associated with these standard procedures. For instance, in patients with severe burns, there are insufficient skin areas to be harvested for skin grafting and the patient can be in critical conditions secondary to sepsis or fluid loss. In contrast, skin grafts generated from cultured epidermal stem cells have advantages compared to the traditional skin grafting. In this section, we will focus on these leading-edge techniques for the treatment of cutaneous wounds.

\section{BACKGROUND}

Mammalian skin epidermis is composed of interfollicular epidermis (IFE), hair follicles (HFs), sebaceous glands (SGs), and eccrine sweat glands, which have their own stem cell populations in each component. ${ }^{1,2}$ For IFE, skin homeostasis and wound repair are sustained by stem cells and the progenitors, which are localized within the basal layer (Fig. 1) of the skin epithelium..$^{3-13}$ In addition to IFE stem cells, some epidermal stem cell populations are located at skin appendages, such as HFs and sweat glands. ${ }^{9,10}$ Although IFE stem cells are unipotent in contrast to the multipotent HF stem cells, stem cells and progenitors in IFE are distinct from HF populations, which are essential for maintaining IFE homeostasis. ${ }^{3,6}$ Based on previous studies, human

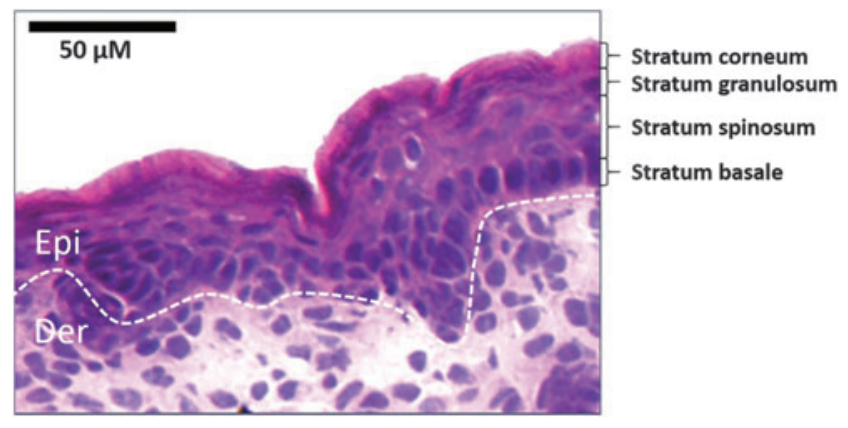

Figure 1. Epidermal stratification in mouse model. HE staining is performed in WT mouse embryonic 18.5-day skin section. Epidermal stratification layers are labeled as indicated. Dotted lines denote dermalepidermal boundaries. Der, dermis; Epi, epidermis.
IFE stem cells possess high level of $\beta_{1}$ and $\alpha_{6}$ integrins, Leu-rich repeats and immunoglobulin-like domains 1 (LRIG1), and melanoma-associated chondroitin sulfate proteoglycan (MCSP) ${ }^{8,14-18}$ In contrast, human and murine HF bulge stem cells possess markers of clusters of differentiation 34 (CD34) and keratin 15 (K15). ${ }^{14,19-21}$ All the pools of skin stem cells contribute to epidermal homeostasis and wound healing.

A noteworthy aspect of wound healing process is that there are certain skin components that may not fully recover after wound closure upon adult skin wound healing. Although in adult mouse skin, HFs process the ability of neogenesis after a 1$2.25 \mathrm{~cm}^{2}$ full-thickness skin excision, ${ }^{22}$ the regeneration of HFs in patients with critical injuries, such as severe burns, has been a challenge in clinic. If the wound only affects epidermis, basal progenitors within sweat ducts have the ability of selfrepair. ${ }^{10}$ However, full-thickness skin wounds, such as severe burns, could cause complete loss of sweat gland regeneration. ${ }^{23}$ Moreover, the scar tissue of the healed epidermis is different from intact skin, since the normal connections between the epidermis and dermis are lost after wound healing. ${ }^{24-27}$ In addition, pigmentation commonly vanishes during wound healing, especially after severe wounds.

\section{DISCUSSION}

\section{Skin wound healing is a highly regulated process that involves essential functions of various cell types}

Adult skin wound healing is commonly divided into four phases (Fig. 2) that spatiotemporally overlaps:

Hemostasis. If the injury reaches beyond the epidermal layer, blood vessels are damaged and

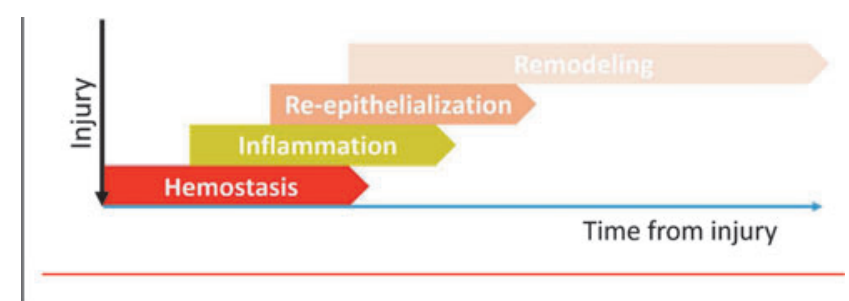

Figure 2. Diagram of wound healing stages. As the injury happens, wound healing process initiates immediately and is classically divided into four stages: hemostasis, inflammation, reepithelialization, and remodeling. These four stages are spatial-temporal overlapping and can continue up to 1 year after wounding. 
cause hemorrhage. Instantly, blood clotting forms a provisional wound matrix. Thrombocytes not only assist the formation of a blood clot but also facilitate the activation of the second phase of wound healing by secreting mediators such as growth factors (discussed in the next section). Moreover, fibronectin, thrombospondin, and vitronectin, as well as the cleavage of fibrinogen, fill the blood clot with cross-linked fibrin molecules, which serve as a bridge for the migration of keratinocytes, blood cells, and endothelial cells. ${ }^{28,29}$

Inflammation. Growth factors and cytokines such as Interleukin (IL)-1, IL-6, and tumor necrosis factor (TNF)- $\alpha$, which are secreted by platelets and leukocytes, initiate the second stage of wound healing. Meanwhile, many other chemotactic molecules secreted during the inflammatory cascade are essential for the later phases of wound healing: Fibroblast growth factor (FGF)-2, insulin-like growth factor (IGF)-1, and transforming growth factor (TGF)- $\beta$ activate the collagen synthesis; TGF- $\beta$ stimulates fibroblast differentiation into myofibroblasts; FGF-2, vascular endothelial growth factor (VEGF)-A, and TGF- $\beta$ initiate angiogenesis; epidermal growth factor (EGF), FGF-2, IGF-1, and TGF- $\alpha$ support reepithelialization. ${ }^{30-45}$

As soon as a couple of minutes after injury, neutrophils are recruited to the wound as essential warriors against potential pathogenic infections, since they secrete effective antimicrobial molecules and proteinases. ${ }^{46}$ Neutrophils are also a source of cytokines (e.g., IL- $1 \alpha, \mathrm{IL}-1 \beta$, and TNF- $\alpha$ ) for the attraction and activation of other cells, amplifying the inflammatory cascade. ${ }^{47,48}$

Macrophages migrate to the wound shortly after neutrophils arrive, cleaning up pathogens and cell debris through phagocytosis. ${ }^{49,50}$ In addition, macrophages will promote keratinocyte migration and fibroblast matrix synthesis, by secreting cytokines and growth factors like TGF- $\beta$, TGF- $\alpha$, heparin-binding-EGF, FGFs, and platelet-derived growth factor. ${ }^{51,52}$

Reepithelialization: the contribution of epidermal stem cells during skin wound healing. The third phase of wound healing is dedicated to reepithelialization, or in other words, "the recreation of an intact keratinocyte layer". ${ }^{53}$ The contribution of IFE stem cells and their progenitors is well illustrated in previous studies. ${ }^{6,54}$ The long-term stem cells even contribute more extensively to skin regeneration compared to the progenitor cells during wound healing. ${ }^{6}$ Since basal keratinocytes include IFE stem cells and all the proliferative progenitors at IFE, we simply refer the whole population as basal keratinocytes. First of all, basal keratinocytes at the wound's edges are activated and migrate along the upper layer of blood clot (Fig. 3). Detailed mechanisms regarding keratinocyte activation, migration, and fusion are reviewed by Jacinto et al. ${ }^{55}$ In general, the hemidesmosome attachments through which basal keratinocytes anchor themselves to the basal lamina need to be dissolved before the migration can occur. The physical and physiological damages at the wound will directly cause calcium influx to the damaged front row cells, which activates AP-1 signaling. ${ }^{55-57}$ Calcium influx also leads to the reorganization of the intracellular tonofilaments in keratinocytes, which prepares cell migration. Moreover, the expression of new integrins on leading edge keratinocytes, ${ }^{58-60}$ the assembly of actin filament networks, as well as the formation and turnover of focal adhesions between keratinocytes and various extracellular matrix components, are required for keratinocyte migration. ${ }^{61-63}$

There is strong evidence showing that microtubules and filamentous actin (F-actin) are coordinately regulating cell migration, potentially through controlling focal adhesion dynamics. ${ }^{64}$ Studies on the mechanisms coordinating cytoskeletal-focal adhesion dynamics during keratinocyte migration are crucial to understanding cell behaviors during wound healing. Our group is dedicated to this field, and we have uncovered the essential role of mammalian spectraplakin actin crosslinking factor 7 (ACF7) in regulating cytoskeletalfocal adhesion dynamics and cell migration. ${ }^{64-67}$ We have found that ACF7 has ATPase activity, which is crucial in targeting microtubules to focal adhesions by tracking along $\mathrm{F}$-actin. ${ }^{64}$ In addition, the phosphorylation of ACF7 plays an essential role in promoting focal adhesion dynamics and in vivo epidermal migration. ${ }^{66,67} \mathrm{We}$ also found that keratinocyte migration and focal adhesion dynamics require interactions between HCLS1-associated protein X-1 (Hax1) and microtubule end-binding protein 2 (EB2) ${ }^{65}$

Keratinocytes at the leading edge need to dissolve the blood clot to pass through and migrate forward. It has been reported that migrating keratinocytes upregulate the expression of the activators and the receptor of urokinase-type plasminogen activator, which can activate plasmin, a fibrinolytic enzyme. ${ }^{68-70}$ In addition, leading edge keratinocytes upregulate the expression of matrix metalloproteinase (MMP) family proteins, such as MMP-1, MMP-9, and MMP-10. ${ }^{71-74}$ Furthermore, 


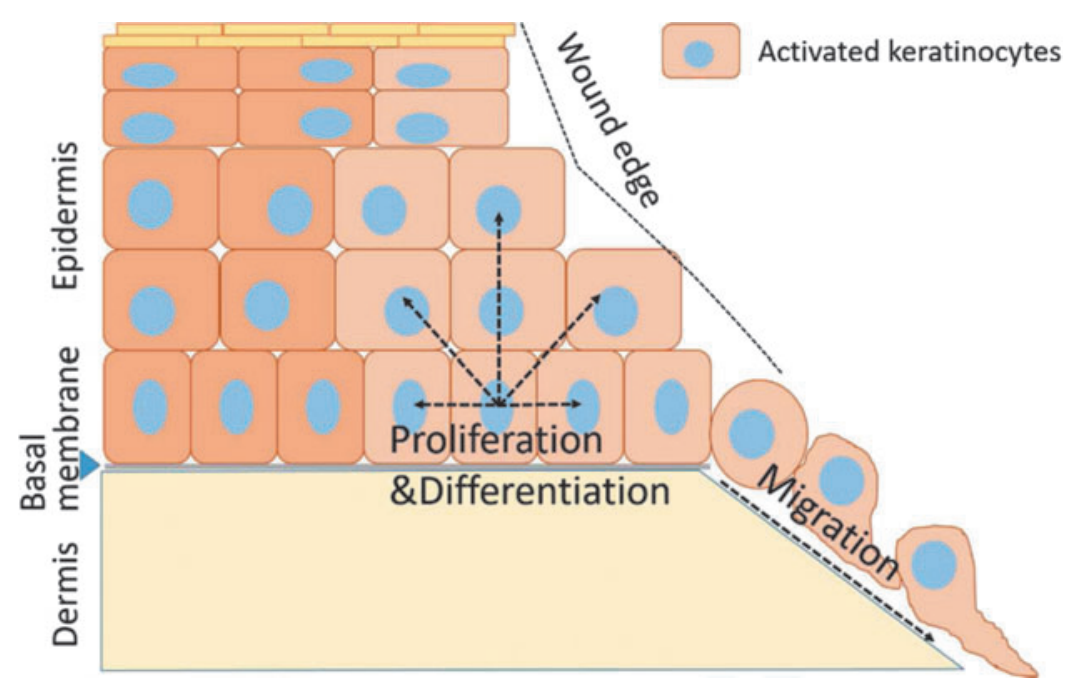

Figure 3. Epidermal stem cells contribute to cutaneous wound healing. Basal keratinocytes at the wound edges are activated and initiate changes in cell morphology, as well as migration ability. The keratinocytes at the leading edge migrate along the upper layer of blood clot, while the basal keratinocytes behind the front line start to proliferate and differentiate, restoring the barrier function of the epithelium.

the migration behavior of keratinocytes is directed by lamellipodia crawling, regulated by small GTPases such as Rho GTPases. Ras is an indispensable regulator of Rho GTPases, cycling and inhibiting Ras will impede cell movement. ${ }^{55,75}$

As the keratinocytes at the leading edge migrate, IFE stem cells and the progenitors behind the front line begin to proliferate and restore the barrier function of the epithelium. ${ }^{53,61}$ The EGF families of growth factors are key regulators of basal keratinocyte proliferation, and they are abundantly released at the wound. ${ }^{41}$ Gradually, the migrating keratinocytes generate a barrier between the eschar and the underlying tissue, while epithelia from opposing directions fuse and close the wound. Then keratinocytes undergo a standard differentiation process and restore the epithelium.

If the stumps of HFs and SGs at the wound site are intact, skin stem cells at the HF and sweat glands also play a role in facilitating wound healing. ${ }^{10,22,76}$ After injury, stem cells at the HF bulge and sweat duct spread out. The release of contact inhibition and the migration process are similar to basal keratinocytes: in parallel to the basal keratinocytes behind the leading edge, which are undergoing fast proliferation, these dispersed $\mathrm{HF}$ and sweat gland stem cells provide a source of extra proliferating cells to facilitate the covering of wound surface. However, the contribution of $\mathrm{HF}$ stem cells is transient during acute wound repair since these cells disappeared from the newly formed epidermis after several weeks. ${ }^{77}$ Moreover, as mentioned earlier, the regeneration of HFs and sweat glands in patients with severe wounds is challenging.

Besides basal keratinocytes, local fibroblasts immigrate through the provisional wound matrix, proliferate and synthesize collagen III, fibronectin, and other components to form a new mechanical structure, closing the tissue gap at the wound. ${ }^{78}$ There is a paracrine signaling loop between keratinocytes and fibroblasts, which promotes keratinocyte proliferation and the fibroblast secretion of cytokines and growth factors important in wound healing. ${ }^{79-84}$ Furthermore, neovascularization/angiogenesis also occurs during the reepithelialization process, restoring the vascular system and resuming nutrient supply. ${ }^{29,85-89}$ By the end of the third phase, a granulation tissue comprising fibroblasts, immune cells, capillaries, and collagens forms at the wound site.

Remodeling. The last phase of wound healing approximately occurs between 1 week and up to 1 year after wounding. At this stage, collagen III is replaced by collagen I while fibroblasts differentiate into myofibroblasts stimulated by TGF- $\beta 1$ and other growth factors. ${ }^{35,90}$ Myofibroblasts express $\alpha$-smooth muscle actin and generate wound contractions like smooth muscle cells by combining collagen I, which decreases the scar surface. ${ }^{91,92}$ In addition, the granulation tissue stops growing due to cell apoptosis within it, which as a result makes the mature wound tissue avascular and acellular, also known as scar formation. ${ }^{93}$ 
Epidermal stem cells are essential components when skin grafting over an open cutaneous wound

Skin grafting is commonly used when the wound site is largely open or the wound has been unable to heal by secondary intentional alone. There are two types of skin grafting, full-thickness skin grafts (FTSGs) and split-thickness skin grafts (STSGs). While both FTSGs and STSGs contain the entire epidermis, STSGs only comprise part of the dermis and FTSGs retain the full dermis. Skin grafts can be autografts, homografts, or xenografts, although autografts are preferred when feasible due to the critical immune compatibility between the grafting and recipient tissues. Although both FTSGs and STSGs are standard of care, they can cause significant morbidity of the donor site after harvesting. Therefore, epidermal skin grafts (ESGs) act as an alternative since only the epidermal layer is harvested without anesthesia at donor site. ${ }^{94}$ The donor area heals quickly with decreased morbidity and additionally provides rapid coverage, as well as restores skin functions at the wound site. However, ESGs are only applicable when the wound size is not too large and when only the epidermis is needed. Moreover, it requires a more optimized wound environment to support the grafted epidermis.

In these different types of skin grafts, the process through which donor skin tissue is taken in the wound is identical to that of wound healing. ${ }^{95}$ Therefore, IFE stem cells and the progenitors within the grafts are important in reassuring the rapid healing of graft skin when the stem cell populations on the original wound edges are too far apart or lose the ability to heal the wound. Moreover, epidermis in ESGs might simulate wound healing through growth factors and cytokines secreted by the keratinocytes in the graft. ${ }^{96}$

\section{Skin grafts generated from cultured keratinocytes (IFE stem cells)}

Cultured epithelial autograft. Since the 1940's, many studies focusing on cultured human epidermal cells have been carried out. ${ }^{97-99}$ It was reported in 1975 that human keratinocytes can be cultured in a serial culture, and keratinocytes in the culture will form stratified squamous epithelium. ${ }^{100}$ Later, another study reported that multiple stratified colonies would ultimately fuse and form an epithelium suitable for grafting. ${ }^{101}$ Cultured human keratinocytes display three distinct morphologies as follows: holoclone, paraclone, and meraclone. ${ }^{102}$ The holoclone cells have long-term proliferative potential and have been considered as epidermal stem/progenitor cells. ${ }^{102}$ The ability of cultured keratinocytes to generate skin grafts relies on epidermal stem cells. ${ }^{5,8,15,102-106}$

Since then, scientists have developed a procedure called cultured epithelial autograft (CEA) where the patient's own healthy skin is harvested, cultured, and grown in vitro on human, mouse, or artificial matrices. Then, cultured epidermis (or with culture matrices) is transferred back to the patient's wound location. CEA is based on the rapid multiplying ability of epithelial cells, more specifically IFE stem cells and the progenitors.

Through years of development, ${ }^{103,107-112}$ CEA has become an alternative method to obtaining epidermal graft and treating major burns (burns $\geq 20 \%$ of total body surface area [TBSA] in adult). This is because in patients with severe burns, there are insufficient skin areas to be harvested for STSGs. Moreover, there is urgent need to protect the patient from infection and fluid loss. In 2010, it was reported that the final graft take of CEA in 88 patients is $72.7 \%$, with a $91 \%$ overall survival (OS) rate. ${ }^{113}$ In 2007, Epicel ${ }^{\circledR}$ (Genzyme Biosurgery) was approved by the U.S. Food and Drug Administration (FDA) to be used in patients with deep dermal or full thickness burns (TBSA $\geq 30 \%$ ).

Recently, CEA has been suggested to be used in the treatment of chronic wounds. ${ }^{114,115}$ Zöller et al. showed that functional CEA has equivalent features of a differentiated epidermis, and together with wound dressings comprising of fibroblasts and other important cells, CEA can be suitable in treating patients with severe chronic wounds. ${ }^{115}$

However, there are debates concerning the disadvantages of CEA. ${ }^{116-120}$ First of all, CEA requires a long expansion time ( 3 weeks) in vitro and requires labor-intensive preparation. ${ }^{117,118}$ Moreover, patients with CEA are vulnerable to infections, which cause variabilities and early graft failures. ${ }^{120}$ In addition, one case report argues that CEA lacks long-term durability due to the occurrence of blistering and sloughing after an early successful coverage of CEA. ${ }^{116}$ Therefore, patients with CEA may stay in the hospital longer and require further reconstructive surgeries. ${ }^{119}$ Nevertheless, CEA is still a valuable strategy for lifesaving and the early treatment of severe wounds. ${ }^{119}$

Isolated keratinocyte grafts. To resolve the deficiencies of CEA, instead of expanded differentiated keratinocytes, cultured preconfluent keratinocytes are used for transplantation, known as isolated keratinocyte grafts. Since the differentiation and merging process of the grafts occur in vivo instead of in culture, it reduces the amount of time required for in vitro culture. Moreover, the grafted keratinocytes 
multiply more actively in vivo and produce a more robust epithelialization since the limited in vitro culture keeps the cells more intact. ${ }^{121}$

There are two types of isolated keratinocyte grafts: keratinocyte autografts and allografts. Keratinocyte autografts were proposed in the 1950 's in animal models. ${ }^{122}$ In 1994 , cell spray of an aerosol cell suspension prepared from in vitro cultured autologous keratinocytes was introduced to treat patients with burns involving 50\% TBSA. ${ }^{123}$ The same group of clinicians, through 11 years of experience, developed a unique method for harvesting and applying cell suspension to help wound closure, called ReCell ${ }^{\circledR}$ (Avita Medical). First, a postage stamp size of a split-thickness skin biopsy is harvested from the patient. Then, the cell suspension is generated after dissolving the cell-to-cell connections using a proprietary solution. Finally, a spray applicator or a syringe is used to apply the suspended cell to the wound site.

The cell suspension derived from patient's healthy skin contains critical cell types required for wound healing, such as undifferentiated basal keratinocytes (IFE stem cells), fibroblasts, melanocytes, and immune cells. ${ }^{124}$ Once applied, the responsive epithelial cells migrate across the wound surface area (similar to the canonical wound healing process), helping to generate healing tissues that have normal color and textures. In addition, the cytokine cross-talks between the damaged tissue and the newly introduced cells, as well as among cell suspension populations, might accelerate the wound healing process. Therefore, ReCell is proposed to have benefits such as minimizing the size of donor skin needed, expediting the healing process, minimizing scar formation, reintroducing pigmentation to the skin, and having the potential to be used by a single clinician in poorer area (Avita Medical).

There are convincing data stating that keratinocyte autografts have beneficial effects. In a randomized trial published in 2007, keratinocyte autografts produce similar results to standard skin grafting, but with the benefits of minor harvesting areas and significantly less postoperative pain. ${ }^{125}$ Another pilot study using keratinocyte autografts to treat chronic nonhealing wounds of more than 6 weeks' duration showed a $73 \%$ healing rate. ${ }^{126}$ More recently, Mcheik et al. ${ }^{127}$ reported a preliminary study during which boys with partial deep severe burns (10\% TBSA) were grafted with foreskin-derived autologous keratinocyte suspensions. They discovered accelerated wound healing with an improved quality of scarring (lack of hypertrophy and pruritus) and pigmentation at the wound site, compared to traditional skin grafts. ${ }^{127}$
They are planning to conduct a further multicenter trial study for severe deep burns. ${ }^{119}$

Although ReCell has been approved in Europe for various dermatologic purposes and has been used in more than 10,000 patients, it has not been approved by FDA. However, there are multiple clinical trials that are either still in progress or have been recently finished (https://clinicaltrials.gov). For instance, there is a prospective randomized pilot study evaluating the safety and effectiveness of ReCell device for venous insufficient leg ulcers. Another clinical trial focuses on the safety and efficacy of the ReCell device in vitiligo and piebaldism patients after conventional $\mathrm{CO}_{2}$ laser ablation or fractional laser treatment. Although the reports are not yet available, various active studies highlight the broadspectrum usage of keratinocyte autografts in the treatment of diverse dermatologic diseases.

In 2008, a medical device similar to ReCell called SkinGun $^{\mathrm{TM}}$ was developed by Gerlach and colleagues. It is slightly different from ReCell since after undamaged skin is taken through biopsy, healthy stem cells are isolated and cultured in a laboratory, whereas ReCell is a one step process. Moreover, SkinGun utilizes an electronically controlled spraying device that helps to keep the stem cells intact during procedures. Since 2008, SkinGun have been used to treat over a dozen patients in Germany and America who have suffered from second degree burns. However, SkinGun still remains an experimental method that requires further testing and research.

Another type of isolated keratinocyte grafts is keratinocyte allografts. When patients with severe epidermal or dermal injuries lack available donor sites, allogeneic keratinocytes become an alternative in such situations. Since allogeneic cells express foreign class II histocompatibility molecules, immune response can cause complications. However, studies have shown that cultivated allogeneic keratinocytes can largely facilitate wound healing, likely through their interactions with other cell populations and the production of critical cytokines and growth factors by keratinocytes, ${ }^{96}$ although the allocation of allogeneic keratinocytes to the wound is temporary. ${ }^{128-130}$ In a phase 2, multicenter, and randomized clinical trial, HP802-247 ("a novel spray-applied cell therapy containing growth-arrested allogeneic neonatal keratinocytes and fibroblasts") was used to treat chronic venous leg ulcers (VLU). ${ }^{129}$ The primary outcome showed that compared to the placebo group, the reduction in wound area is significantly greater in the patients treated with HP802-247, and the most optimal dosage is $0.5 \times 10^{6}$ cells $/ \mathrm{mL}$ every 14 days. ${ }^{129}$ 
More importantly, new skin ulcers and cellulitis only occurred in 5-6\% patients. ${ }^{129}$ However, HP802-247 failed to show efficacy in two phase 3 clinical trials of treating chronic VLU. ${ }^{131}$ After investigation, the most possible cause of the failure was the age of the cell banks used in phase 3 trials compared to that used in phase 2 trials; the cell banks used in phase 3 trials were 9-12 years old, while the cell banks used in phase 2 trials were 6-8 years old. ${ }^{131}$ Cell behavior test indicated phenotypic changes primarily in the keratinocytes (longer doubling time with decreased cell viability), as well as the changes in culturing conditions to restore keratinocyte doubling time and VEGF production. ${ }^{131}$ It was highly recommended that new cell banks should be established before the new trial and robust characterization of the keratinocyte phenotypes should be ensured. ${ }^{131}$

In terms of treating chronic wounds, Apligraf ${ }^{\circledR}$ (Organogenesis, MA) has been approved by FDA to treat VLU and diabetic foot ulcers (DFU). ${ }^{132-134}$ Apligraf is a bi-layered bioengineered skin substitute; cultured human foreskin-derived neonatal fibroblasts form the "neodermis" layer, while human foreskin-derived neonatal epidermal keratinocytes are cultured and induced to stratify in vitro to form the "neoepidermis" layer. Although Apligraf does not persist permanently after grafting $(<4$ weeks) in most patients, ${ }^{135,136}$ it significantly promotes wound healings, likely through mechanisms such as cytokine secretion and optimizing wound environment. Other than being used to treat VLU and DFU, Apligraf has been reported to facilitate other type of wound healing. For instance, Apligraf was reported to be effective in treating a patient with necrobiosis lipoidica who had multiple chronic wounds. ${ }^{137}$ In addition, Apligraf was applied with hyperbaric oxygen therapy in a patient with a degloving injury, who was also under chronic steroid treatment. ${ }^{138}$ Recently, Apligraf has been reported to facilitate wound healing in premature neonates with full thickness skin and soft tissue necrosis at the dorsum of the right hand caused by total parenteral nutrition induced extravasation. ${ }^{139}$

\section{SUMMARY}

The biological process of cutaneous wound healing is regulated by many types of cellular functions. Epidermal stem cells are crucial for wound coverage and restoring epidermal function. Therefore, the mechanisms controlling keratinocyte activation, migration, and fusion give rise to fundamental questions that need to be answered.
Our group is dedicated to understanding the mechanisms coordinating cytoskeletal dynamics during keratinocyte migration, which is crucial to comprehending the cell behaviors during wound healing. Our previous study has provided critical insights into the mechanics of cell-adhesion dynamics. ${ }^{64-67}$ We will look further into the complex signaling networks controlling the cross talk between different cytoskeletal networks.

The crucial function of epidermal stem cells during skin wound healing has intrigued the development of stem cell therapies, as well as tissue engineering for therapeutic purposes in clinic. As mentioned, both traditional skin grafting procedures and advanced keratinocyte grafting techniques are based upon the fundamental role of somatic skin stem cells during wound healing process. However, the majority of leading techniques still retain some deficiencies during clinical use, such as requiring improvement in decreasing vulnerability to infections and increasing long-term durability. Most importantly, the appendages under the epidermis, such as HFs and sweat glands, merely have the ability to regenerate after severe injuries. Although pigmentation is improved by keratinocyte grafting, the regaining of skin cosmesis, sensitivity, elasticity, and normal appendage is still difficult to pursue through available treatment approaches. Therefore, there are urgent inquires to improve the current standard of care and to develop novel techniques such as human skin substitutes to improve patient outcomes and long-term rehabilitation.

\section{ACKNOWLEDGMENTS AND FUNDING SOURCES}

The authors thank all the coauthors contributing to this article. This work was supported by a grant R01-AR063630 from the National Institutes of Health, the Research Scholar Grant (RSG-13198-01) from the American Cancer Society, and the V scholar award from V foundation to X.W.

\section{AUTHOR DISCLOSURE AND GHOSTWRITING}

No competing financial interests exist. The content of this article was expressly written by the author(s) listed. No ghostwriters were used to write this article. 


\section{ABOUT THE AUTHORS}

Yuanyuan Li, MS, is a $\mathrm{PhD}$ candidate in the Committee on Cancer Biology, Division of Biological Sciences at the University of Chicago. Jamie Zhang is a senior student at Naperville Central High School. Jiping Yue, PhD, is a postdoctoral fellow in Dr. Xiaoyang Wu's laboratory, at Ben May
Department for Cancer Research, the University of Chicago. Xuewen Gou, MS, is a laboratory technologist in Dr. Xiaoyang Wu's laboratory, at Ben May Department for Cancer Research, the University of Chicago. Xiaoyang Wu, PhD, is an Assistant Professor at Ben May Department for Cancer Research, the University of Chicago.

\section{REFERENCES}

1. Donati G, Watt FM. Stem cell heterogeneity and plasticity in epithelia. Cell Stem Cell 2015;16: 465-476.

2. Watt FM. Mammalian skin cell biology: at the interface between laboratory and clinic. Science 2014;346:937-940.

3. Clayton E, Doupe DP, Klein AM, Winton DJ, Simons BD, Jones PH. A single type of progenitor cell maintains normal epidermis. Nature 2007:446:185-189

4. Blanpain C, Horsley V, Fuchs E. Epithelial stem cells: turning over new leaves. Cell 2007;128:445-458.

5. Alonso L, Fuchs E. Stem cells of the skin epithelium. Proc Natl Acad Sci U S A 2003;100 Suppl 1:11830-11835.

6. Mascre G, Dekoninck S, Drogat B, et al. Distinct contribution of stem and progenitor cells to epidermal maintenance. Nature 2012;489:257262.

7. Hsu YC, Li L, Fuchs E. Emerging interactions between skin stem cells and their niches. Nat Med 2014;20:847-856.

8. Watt FM. The stem cell compartment in human interfollicular epidermis. J Dermatol Sci 2002;28: 173-180.

9. Blanpain C, Fuchs E. Epidermal homeostasis: a balancing act of stem cells in the skin. Nat Rev Mol Cell Biol 2009;10:207-217.

10. Lu CP, Polak L, Rocha AS, et al. Identification of stem cell populations in sweat glands and ducts reveals roles in homeostasis and wound repair. Cell 2012;150:136-150.

11. Koster MI, Roop DR. Mechanisms regulating epithelial stratification. Annu Rev Cell Dev Biol 2007:23:93-113.

12. Mack JA, Anand S, Maytin EV. Proliferation and cornification during development of the mammalian epidermis. Birth Defects Res C Embryo Today 2005;75:314-329.

13. Milstone LM. Epidermal desquamation. J Dermatol Sci 2004;36:131-140.

14. Kretzschmar K, Watt FM. Markers of epidermal stem cell subpopulations in adult mammalian skin. Cold Spring Harbor Perspect Med 2014;4 pii: a013631.
15. Jones PH, Watt FM. Separation of human epidermal stem cells from transit amplifying cells on the basis of differences in integrin function and expression. Cell 1993;73:713-724.

16. Li A, Simmons PJ, Kaur P. Identification and isolation of candidate human keratinocyte stem cells based on cell surface phenotype. Proc Natl Acad Sci U S A 1998;95:3902-3907.

17. Legg J, Jensen UB, Broad S, Leigh I, Watt FM Role of melanoma chondroitin sulphate proteoglycan in patterning stem cells in human interfollicular epidermis. Development 2003;130: 6049-6063.

18. Jensen KB, Watt FM. Single-cell expression profiling of human epidermal stem and transitamplifying cells: Lrig1 is a regulator of stem cell quiescence. Proc Natl Acad Sci U S A 2006; 103:11958-11963

19. Trempus CS, Morris RJ, Bortner CD, et al. Enrichment for living murine keratinocytes from the hair follicle bulge with the cell surface marker CD34. J Invest Dermatol 2003;120:501-511.

20. Lyle S, Christofidou-Solomidou M, Liu Y, Elder DE, Albelda S, Cotsarelis G. The C8/144B monoclonal antibody recognizes cytokeratin 15 and defines the location of human hair follicle stem cells. J Cell Sci 1998;111 (Pt 21):3179-3188.

21. Morris RJ, Liu Y, Marles L, et al. Capturing and profiling adult hair follicle stem cells. Nat Biotechnol 2004;22:411-417.

22. Ito $M$, Yang Z, Andl T, et al. Wnt-dependent de novo hair follicle regeneration in adult mouse skin after wounding. Nature 2007:447:316-320.

23. Fu XB, Sun TZ, Li XK, Sheng ZY. Morphological and distribution characteristics of sweat glands in hypertrophic scar and their possible effects on sweat gland regeneration. Chin Med J 2005;118: 186-191.

24. Ehrlich HP, Desmouliere A, Diegelmann RF, et al. Morphological and immunochemical differences between keloid and hypertrophic scar. Am J Pathol 1994;145:105-113.

25. Desmouliere A, Redard M, Darby I, Gabbiani G. Apoptosis mediates the decrease in cellularity during the transition between granulation tissue and scar. Am J Pathol 1995;146:56-66.
26. Ehrlich HP, Rajaratnam JB. Cell locomotion forces versus cell contraction forces for collagen lattice contraction: an in vitro model of wound contraction. Tissue Cell 1990;22:407-417.

27. Hembry RM, Bernanke DH, Hayashi K, Trelstad RL, Ehrlich HP. Morphologic examination of mesenchymal cells in healing wounds of normal and tight skin mice. Am J Pathol 1986;125:81-89.

28. Martin P. Wound healing-aiming for perfect skin regeneration. Science 1997;276:75-81.

29. Reinke JM, Sorg H. Wound repair and regeneration. Eur Surg Res 2012;49:35-43

30. Broadley KN, Aquino AM, Woodward SC, et al. Monospecific antibodies implicate basic fibroblast growth factor in normal wound repair. Lab Invest 1989;61:571-575.

31. Ortega S, Ittmann M, Tsang SH, Ehrlich M, Basilico C. Neuronal defects and delayed wound healing in mice lacking fibroblast growth factor 2. Proc Natl Acad Sci U S A 1998;95:5672-5677.

32. Ghahary A, Shen YJ, Nedelec B, Scott PG, Tredget EE. Enhanced expression of mRNA for insulin-like growth factor-1 in post-burn hypertrophic scar tissue and its fibrogenic role by dermal fibroblasts. Mol Cell Biochem 1995;148: 25-32.

33. Bitar MS. Insulin and glucocorticoid-dependent suppression of the IGF-I system in diabetic wounds. Surgery 2000;127:687-695.

34. Bitar MS, Labbad ZN. Transforming growth factor-beta and insulin-like growth factor-I in relation to diabetes-induced impairment of wound healing. J Surg Res 1996;61:113-119.

35. Desmouliere A, Geinoz A, Gabbiani F, Gabbiani G. Transforming growth factor-beta 1 induces alpha-smooth muscle actin expression in granulation tissue myofibroblasts and in quiescent and growing cultured fibroblasts. J Cell Biol 1993;122:103-111.

36. Brown RL, Ormsby I, Doetschman TC, Greenhalgh DG. Wound healing in the transforming growth factor-beta-deficient mouse. Wound Repair Regen 1995;3:25-36

37. Roberts AB, Sporn MB, Assoian RK, et al Transforming growth factor type beta: rapid induction of fibrosis and angiogenesis in vivo and 
stimulation of collagen formation in vitro. Proc Natl Acad Sci U S A 1986;83:4167-4171.

38. Howdieshell TR, Callaway D, Webb WL, et al. Antibody neutralization of vascular endothelial growth factor inhibits wound granulation tissue formation. J Surg Res 2001;96:173-182.

39. Nissen NN, Polverini PJ, Koch AE, Volin MV, Gamelli RL, DiPietro LA. Vascular endothelial growth factor mediates angiogenic activity during the proliferative phase of wound healing. Am J Pathol 1998:152:1445-1452.

40. Tsou R, Fathke C, Wilson L, Wallace K, Gibran N, Isik F. Retroviral delivery of dominant-negative vascular endothelial growth factor receptor type 2 to murine wounds inhibits wound angiogenesis. Wound Repair Regen 2002;10:222-229.

41. Grotendorst GR, Soma Y, Takehara K, Charette M. EGF and TGF-alpha are potent chemoattractants for endothelial cells and EGF-like peptides are present at sites of tissue regeneration. J Cell Physiol 1989;139:617-623.

42. Cribbs RK, Harding PA, Luquette MH, Besner GE. Endogenous production of heparin-binding EGFlike growth factor during murine partial-thickness burn wound healing. J Burn Care Rehabil 2002; 23:116-125.

43. Wenczak BA, Lynch JB, Nanney LB. Epidermal growth factor receptor distribution in burn wounds. Implications for growth factor-mediated repair. J Clin Invest 1992;90:2392-2401.

44. Sunkari VG, Lind F, Botusan IR, et al. Hyperbaric oxygen therapy activates hypoxia-inducible factor 1 (HIF-1), which contributes to improved wound healing in diabetic mice. Wound Repair Regen 2015;23:98-103.

45. Werner S, Grose R. Regulation of wound healing by growth factors and cytokines. Physiol Rev 2003;83:835-870.

46. Weiss SJ. Tissue destruction by neutrophils. N Engl J Med 1989;320:365-376.

47. Daley JM, Reichner JS, Mahoney EJ, et al. Modulation of macrophage phenotype by soluble product(s) released from neutrophils. J Immunol 2005;174:2265-2272.

48. Eming SA, Krieg T, Davidson JM. Inflammation in wound repair: molecular and cellular mechanisms. J Invest Dermatol 2007;127:514-525.

49. Profyris C, Tziotzios C, Do Vale I. Cutaneous scarring: pathophysiology, molecular mechanisms, and scar reduction therapeutics Part I. The molecular basis of scar formation. J Am Acad Dermatol 2012;66:1-10; quiz 11-12.

50. Tziotzios C, Profyris C, Sterling J. Cutaneous scarring: pathophysiology, molecular mechanisms, and scar reduction therapeutics Part II. Strategies to reduce scar formation after dermatologic procedures. J Am Acad Dermatol 2012;66:13-24; quiz 25-16.

51. Leibovich SJ, Ross R. The role of the macrophage in wound repair. A study with hydrocor- tisone and antimacrophage serum. Am J Pathol 1975;78:71-100.

52. DiPietro LA, Polverini PJ. Role of the macrophage in the positive and negative regulation of wound neovascularization. Behring Inst Mitt 1993:238-247.

53. Gurtner GC, Werner S, Barrandon Y, Longaker MT. Wound Repair Regen Nat 2008:453:314-321.

54. Langton AK, Herrick SE, Headon DJ. An extended epidermal response heals cutaneous wounds in the absence of a hair follicle stem cell contribution. J Invest Dermatol 2008;128:1311-1318.

55. Jacinto A, Martinez-Arias A, Martin P. Mechanisms of epithelial fusion and repair. Nat Cell Biol 2001;3:E117-E123.

56. Martin P, Nobes CD. An early molecular component of the wound healing response in rat embryos -induction of c-fos protein in cells at the epidermal wound margin. Mech Dev 1992;38:209-215.

57. Okada Y, Saika S, Hashizume N, et al. Expression of fos family and jun family protooncogenes during corneal epithelial wound healing. Curr Eye Res 1996;15:824-832.

58. Cavani A, Zambruno G, Marconi A, Manca V, Marchetti M, Giannetti A. Distinctive integrin expression in the newly forming epidermis during wound healing in humans. J Invest Dermatol 1993;101:600-604.

59. Breuss JM, Gallo J, DeLisser HM, et al. Expression of the beta 6 integrin subunit in development, neoplasia and tissue repair suggests a role in epithelial remodeling. J Cell Sci 1995;108 (Pt 6):2241-2251.

60. Haapasalmi K, Zhang K, Tonnesen M, et al. Keratinocytes in human wounds express alpha $v$ beta 6 integrin. J Invest Dermatol 1996;106:42-48.

61. Singer AJ, Clark RA. Cutaneous wound healing. N Engl J Med 1999;341:738-746.

62. Boudreau N, Myers C, Bissell MJ. From laminin to lamin: regulation of tissue-specific gene expression by the ECM. Trends Cell Biol 1995;5:1-4.

63. Conrad PA, Giuliano KA, Fisher G, Collins K, Matsudaira PT, Taylor DL. Relative distribution of actin, myosin I, and myosin II during the wound healing response of fibroblasts. J Cell Biol 1993;120:1381-1391.

64. Wu X, Kodama A, Fuchs E. ACF7 regulates cytoskeletal-focal adhesion dynamics and migration and has ATPase activity. Cell 2008;135: 137-148.

65. Liu H, Yue J, Huang H, et al. Regulation of focal adhesion dynamics and cell motility by the EB2 and Hax1 protein complex. J Biol Chem 2015;290:30771-30782

66. Wu X, Shen OT, Oristian DS, et al. Skin stem cells orchestrate directional migration by regulating microtubule-ACF7 connections through GSK3beta. Cell 2011;144:341-352.
67. Yue J, Zhang Y, Liang WG, et al. In vivo epidermal migration requires focal adhesion targeting of ACF7. Nat Commun 2016;7:11692.

68. Grondahl-Hansen J, Lund LR, Ralfkiaer E, Ottevanger $\mathrm{V}$, Dano K. Urokinase- and tissue-type plasminogen activators in keratinocytes during wound reepithelialization in vivo. J Invest Dermatol 1988;90:790-795.

69. Romer J, Lund LR, Eriksen J, Pyke C, Kristensen $P$, Dano K. The receptor for urokinase-type plasminogen activator is expressed by keratinocytes at the leading edge during reepithelialization of mouse skin wounds. J Invest Dermatol 1994;102:519-522.

70. Romer J, Lund LR, Eriksen J, et al. Differential expression of urokinase-type plasminogen activator and its type-1 inhibitor during healing of mouse skin wounds. J Invest Dermatol 1991; 97:803-811.

71. Grinnell F, Ho CH, Wysocki A. Degradation of fibronectin and vitronectin in chronic wound fluid: analysis by cell blotting, immunoblotting, and cell adhesion assays. J Invest Dermatol 1992;98:410-416.

72. Saarialho-Kere UK, Pentland AP, BirkedalHansen H, Parks WC, Welgus HG. Distinct populations of basal keratinocytes express stromelysin-1 and stromelysin-2 in chronic wounds. J Clin Invest 1994;94:79-88.

73. Salo T, Makela M, Kylmaniemi M, AutioHarmainen $H$, Larjava $H$. Expression of matrix metalloproteinase-2 and -9 during early human wound healing. Lab Invest 1994;70:176-182.

74. Tarnuzzer RW, Schultz GS. Biochemical analysis of acute and chronic wound environments. Wound Repair Regen 1996;4:321-325.

75. Nobes CD, Hall A. Rho GTPases control polarity, protrusion, and adhesion during cell movement. J Cell Biol 1999;144:1235-1244.

76. Rochat A, Kobayashi K, Barrandon Y. Location of stem cells of human hair follicles by clonal analysis. Cell 1994;76:1063-1073.

77. Ito M, Liu Y, Yang Z, et al. Stem cells in the hair follicle bulge contribute to wound repair but not to homeostasis of the epidermis. Nat Med 2005; 11:1351-1354.

78. Knox P, Crooks S, Rimmer CS. Role of fibronectin in the migration of fibroblasts into plasma clots. J Cell Biol 1986;102:2318-2323.

79. Lau K, Paus R, Tiede S, Day P, Bayat A. Exploring the role of stem cells in cutaneous wound healing. Exp Dermatol 2009;18:921-933.

80. Waelti ER, Inaebnit SP, Rast HP, et al. Co-culture of human keratinocytes on post-mitotic human dermal fibroblast feeder cells: production of large amounts of interleukin 6. J Invest Dermatol 1992;98:805-808.

81. Boxman IL, Ruwhof C, Boerman OC, Lowik CW, Ponec M. Role of fibroblasts in the regulation of proinflammatory interleukin IL-1, IL-6 and IL-8 
levels induced by keratinocyte-derived IL-1. Arch Dermatol Res 1996;288:391-398.

82. Smola H, Thiekotter G, Fusenig NE. Mutual induction of growth factor gene expression by epidermal-dermal cell interaction. J Cell Biol 1993;122:417-429.

83. Werner S, Krieg T, Smola H. Keratinocytefibroblast interactions in wound healing. J Invest Dermatol 2007;127:998-1008.

84. Szabowski A, Maas-Szabowski N, Andrecht S, et al. c-Jun and JunB antagonistically control cytokine-regulated mesenchymal-epidermal interaction in skin. Cell 2000;103:745-755.

85. Brown LF, Yeo KT, Berse B, et al. Expression of vascular permeability factor (vascular endothelial growth factor) by epidermal keratinocytes during wound healing. J Exp Med 1992;176: 1375-1379.

86. Frank S, Hubner G, Breier G, Longaker MT, Greenhalgh DG, Werner S. Regulation of vascular endothelial growth factor expression in cultured keratinocytes. Implications for normal and impaired wound healing. J Biol Chem 1995;270:12607-12613.

87. Peters KG, De Vries C, Williams LT. Vascular endothelial growth factor receptor expression during embryogenesis and tissue repair suggests a role in endothelial differentiation and blood vessel growth. Proc Natl Acad Sci U S A 1993; 90:8915-8919.

88. Failla CM, Odorisio T, Cianfarani F, Schietroma C, Puddu P, Zambruno G. Placenta growth factor is induced in human keratinocytes during wound healing. J Invest Dermatol 2000;115:388-395.

89. Carmeliet P, Moons L, Luttun A, et al. Synergism between vascular endothelial growth factor and placental growth factor contributes to angiogenesis and plasma extravasation in pathological conditions. Nat Med 2001;7:575-583.

90. Grinnell F. Fibroblasts, myofibroblasts, and wound contraction. J Cell Biol 1994;124:401-404.

91. Gurtner GC, Evans GR. Advances in head and neck reconstruction. Plast Reconstr Surg 2000; 106:672-682; quiz 683.

92. Skalli 0, Schurch W, Seemayer T, et al. Myofibroblasts from diverse pathologic settings are heterogeneous in their content of actin isoforms and intermediate filament proteins. Lab Invest 1989;60:275-285.

93. Greenhalgh DG. The role of apoptosis in wound healing. Int J Biochem Cell Biol 1998;30:10191030.

94. Herskovitz I, Hughes OB, Macquhae F, Rakosi A Kirsner R. Epidermal skin grafting. Int Wound J 2016;13 Suppl 3:52-56.

95. Andreassi A, Bilenchi R, Biagioli M, D'Aniello C Classification and pathophysiology of skin grafts. Clin Dermatol 2005;23:332-337.

96. Gauglitz GG, Zedler S, von Spiegel F, Fuhr J, von Donnersmarck GH, Faist E. Functional charac- terization of cultured keratinocytes after acute cutaneous burn injury. PLoS One 2012;7:e29942.

97. Karasek MA. Growth and differentiation of transplanted epithelial cell cultures. J Invest Dermatol 1968;51:247-252.

98. Medawar PB. The cultivation of adult mammalian skin epithelium in vitro. $0 \mathrm{~J}$ Microsc Sci 1948;89:187-196.

99. Pickerill HP. On the possibility of establishing skin banks. Br J Plast Surg 1951:4:157-165.

100. Rheinwald JG, Green H. Serial cultivation of strains of human epidermal keratinocytes: the formation of keratinizing colonies from single cells. Cell 1975;6:331-343.

101. Green H, Kehinde 0, Thomas J. Growth of cultured human epidermal cells into multiple epithelia suitable for grafting. Proc Natl Acad Sci U S A 1979;76:5665-5668.

102. Barrandon $Y$, Green H. Three clonal types of keratinocyte with different capacities for multiplication. Proc Natl Acad Sci U S A 1987;84: 2302-2306.

103. Gallico GG, 3rd, O'Connor NE, Compton CC, Kehinde 0 , Green $\mathrm{H}$. Permanent coverage of large burn wounds with autologous cultured human epithelium. N Engl J Med 1984;311:448-451.

104. Watt FM. Epidermal stem cells in culture. J Cell Sci Suppl 1988;10:85-94.

105. Jones PH, Harper S, Watt FM. Stem cell patterning and fate in human epidermis. Cell 1995; 80:83-93.

106. Tan DW, Jensen KB, Trotter MW, Connelly JT, Broad S, Watt FM. Single-cell gene expression profiling reveals functional heterogeneity of undifferentiated human epidermal cells. Development 2013;140:1433-1444.

107. Grafting of burns with cultured epithelium prepared from autologous epidermal cells. Lancet 1981;1:75-78

108. Bettex-Galland M, Slongo T, Hunziker T, Wiesmann U, Bettex M. Use of cultured keratinocytes in the treatment of severe burns. Zr Kinderchir 1988;43:224-228.

109. Boyce ST, Kagan RJ, Meyer NA, Yakuboff KP, Warden GD. The 1999 clinical research award. Cultured skin substitutes combined with Integra Artificial Skin to replace native skin autograft and allograft for the closure of excised full-thickness burns. J Burn Care Rehabil 1999;20:453-461.

110. Compton CC, Hickerson W, Nadire K, Press W. Acceleration of skin regeneration from cultured epithelial autografts by transplantation to homograft dermis. J Burn Care Rehabil 1993;14: 653-662.

111. Donati L, Magliacani G, Bormioli M, Signorini M, Preis FW. Clinical experiences with keratinocyte grafts. Burns 1992;18 Suppl 1:S19-S26.

112. Langdon RC, Cuono CB, Birchall N, et al. Reconstitution of structure and cell function in human skin grafts derived from cryopreserved allogeneic dermis and autologous cultured keratinocytes. J Invest Dermatol 1988;91:478-485.

113. Sood R, Roggy D, Zieger M, et al. Cultured epithelial autografts for coverage of large burn wounds in eighty-eight patients: the Indiana University experience. J Burn Care Res 2010;31:559-568.

114. Pianigiani E, Andreassi A, Andreassi L. Autografts and cultured epidermis in the treatment of vitiligo. Clin Dermatol 2005;23:424-429.

115. Zöller N, Valesky E, Butting M, et al. Clinical application of a tissue-cultured skin autograft: an alternative for the treatment of non-healing or slowly healing wounds? Dermatology 2014;229: 190-198.

116. Desai MH, Mlakar JM, McCauley RL, et al. Lack of long-term durability of cultured keratinocyte burn-wound coverage: a case report. J Burn Care Rehabil 1991;12:540-545.

117. Harris PA, Leigh IM, Navsaria HA. Pre-confluent keratinocyte grafting: the future for cultured skin replacements? Burns 1998:24:591-593.

118. Jackson DM. The evolution of burn treatment in the last 50 years. Burns 1991;17:329-334.

119. McHeik JN, Barrault C, Levard G, Morel F, Bernard FX, Lecron JC. Epidermal healing in burns: autologous keratinocyte transplantation as a standard procedure: update and perspective. Plast Reconstr Surg Glob Open 2014;2:e218.

120. Paddle-Ledinek JE, Cruickshank DG, Masterton JP. Skin replacement by cultured keratinocyte grafts: an Australian experience. Burns 1997;23:204-211.

121. Adams JC, Watt FM. Changes in keratinocyte adhesion during terminal differentiation: reduction in fibronectin binding precedes alpha 5 beta 1 integrin loss from the cell surface. Cell 1990;63:425-435.

122. Billingham RE, Reynolds J. Transplantation studies on sheets of pure epidermal epithelium and on epidermal cell suspensions. $\mathrm{Br} \mathrm{J}$ Plast Surg 1952:5:25-36.

123. Wood FM, Kolybaba ML, Allen P. The use of cultured epithelial autograft in the treatment of major burn wounds: eleven years of clinical experience. Burns 2006;32:538-544.

124. Chrapusta A, Nessler MB, Drukala J, Bartoszewicz M, Madry R. A comparative analysis of advanced techniques for skin reconstruction with autologous keratinocyte culture in severely burned children: own experience. Postepy Dermatol Alergol 2014;31:164-169.

125. Gravante G, Di Fede MC, Araco A, et al. A randomized trial comparing ReCell system of epidermal cells delivery versus classic skin grafts for the treatment of deep partial thickness burns. Burns 2007:33:966-972.

126. Shukla VK, Tiwary SK, Barnwal S, Gulati AK Pandey SS. Effect of autologous epidermal cell 
suspension transplantation in chronic nonhealing wounds: a pilot study. Can J Surg 2010;53:6-10.

127. McHeik JN, Barrault C, Pedretti N, et al. Foreskin-isolated keratinocytes provide successful extemporaneous autologous paediatric skin grafts. J Tissue Eng Regen Med 2016;10:252-260.

128. Brain A, Purkis $P$, Coates $P$, Hackett $M$, Navsaria $H$, Leigh I. Survival of cultured allogeneic keratinocytes transplanted to deep dermal bed assessed with probe specific for $Y$ chromosome. BMJ 1989;298:917-919.

129. Kirsner RS, Marston WA, Snyder RJ, Lee TD, Cargill DI, Slade HB. Spray-applied cell therapy with human allogeneic fibroblasts and keratinocytes for the treatment of chronic venous leg ulcers: a phase 2, multicentre, double-blind, randomised, placebo-controlled trial. Lancet 2012;380:977-985.

130. Pokorna E, Broz L, Vesely P, Matouskova E. Y chromosome and vimentin used to trace the fate of allogeneic keratinocytes delivered to the wound by the recombined human/pig skin. Folia Biol 2001;47:128-134.

131. Kirsner RS, Vanscheidt W, Keast DH, et al. Phase 3 evaluation of HP802-247 in the treatment of chronic venous leg ulcers. Wound Repair Regen 2016;24:894-903.

132. Zaulyanov L, Kirsner RS. A review of a bi-layered living cell treatment (Apligraf) in the treatment of venous leg ulcers and diabetic foot ulcers. Clin Interv Aging 2007;2:93-98.
133. Veves A, Falanga V, Armstrong DG, Sabolinski ML. Graftskin, a human skin equivalent, is effective in the management of noninfected neuropathic diabetic foot ulcers: a prospective randomized multicenter clinical trial. Diabetes Care 2001;24:290-295.

134. Falanga V, Margolis D, Alvarez 0 , et al. Rapid healing of venous ulcers and lack of clinical rejection with an allogeneic cultured human skin equivalent. Human Skin Equivalent Investigators Group. Arch Dermatol 1998;134:293-300.

135. Phillips TJ, Manzoor J, Rojas A, et al. The Iongevity of a bilayered skin substitute after application to venous ulcers. Arch Dermatol 2002; 138:1079-1081.

136. Hu S, Kirsner RS, Falanga V, Phillips T, Eaglstein WH. Evaluation of Apligraf persistence and basement membrane restoration in donor site wounds: a pilot study. Wound Repair Regen 2006;14:427-433.

137. Penny HL, Faretta M, Rifkah M, Weaver A, Swires A, Spinazzola J. Selective case study describing the use of Apligraf on necrobiosis lipoidica associated with diabetes. J Wound Care 2014;23:S12-S15.

138. Pistorio AL, Leslie J, Gustavson RB, Baynosa RC. Use of HBOT and a living bilayer skin substitute for a compromised flap with chronic steroid use: a case report. J Wound Care 2015;24:34-40.

139. Hirsch SD, Powers JM, Rhodes JL. Neonatal Soft Tissue Reconstruction Using a Bioengineered Skin Substitute. J Craniofac Surg 2017; 28:489-491.

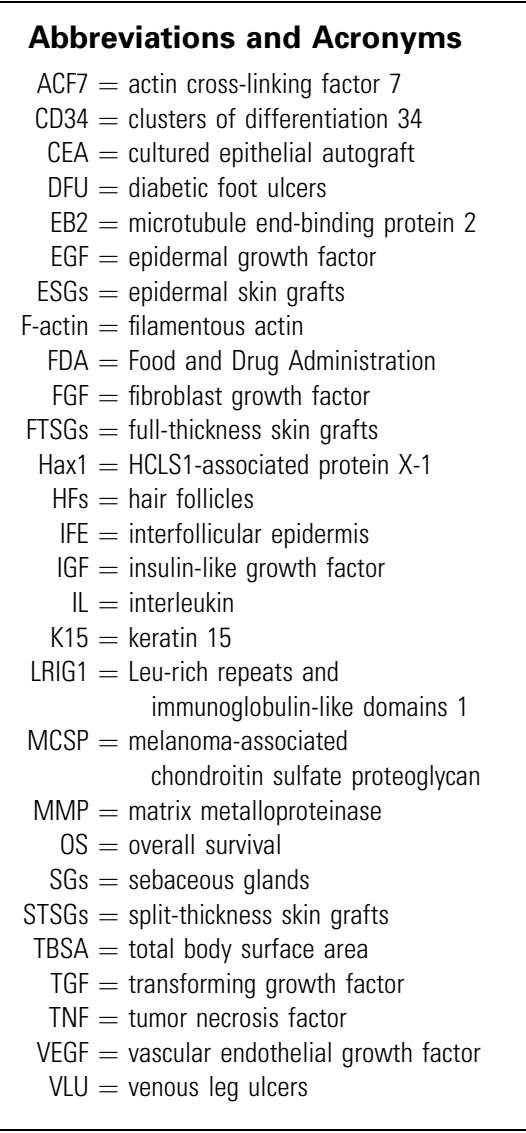

